Research Paper

\title{
Peptide V3 Inhibits the Growth of Human Hepatocellular Carcinoma by Inhibiting the Ras/Raf/MEK/ERK Signaling Pathway
}

\begin{abstract}
Dongdong $\mathrm{Wu}^{1}$, Mengling $\mathrm{Li}^{1}$, Yingran Gao ${ }^{1,3}$, Wenke Tian ${ }^{1}$, Jianmei $\mathrm{Li}^{1}$, Qianqian Zhang ${ }^{1}$, Zhengguo Liu1,


Ailing Ji ${ }^{\circledR}$, Yanzhang $\mathrm{Li}^{1{ }^{凶}}$

1. School of Basic Medical Sciences, Henan University, Kaifeng, Henan 475004, China

2. State Key Laboratory of Tea Plant Biology and Utilization, Anhui Agricultural University, 130 Changiiang West Road, Hefei, Anhui 230036, China

3. Joint National Laboratory for Antibody Drug Engineering, Henan International Joint Laboratory for Nuclear Protein Regulation, Henan University, Kaifeng, Henan 475004, China

$\square$ Corresponding authors: Zhongwen Xie, State Key Laboratory of Tea Plant Biology and Utilization, Anhui Agricultural University, 130 Changjiang West Road, Hefei, Anhui 230036, China. Tel: +86-551-65786153; Fax: +86-551-65786765; E-mail: zhongwenxie@ahau.edu.cn. Ailing Ji, School of Basic Medical Sciences, Henan University, Kaifeng, Henan 475004, China. Tel: +86-371-22868833; Fax: +86-371-23880585; E-mail: ailingii@163.com. Yanzhang Li, School of Basic Medical Sciences, Henan University, Kaifeng, Henan 475004, China. Tel: +86-371-22863897; Fax: +86-371-23880585; E-mail: yanzhang206@163.com.

(1) Ivyspring International Publisher. This is an open access article distributed under the terms of the Creative Commons Attribution (CC BY-NC) license (https://creativecommons.org/licenses/by-nc/4.0/). See http://ivyspring.com/terms for full terms and conditions.
\end{abstract}

Received: 2018.08.14; Accepted: 2019.01.16; Published: 2019.04 .03

\begin{abstract}
Hepatocellular carcinoma $(\mathrm{HCC})$ is one of the leading causes of cancer-related deaths. Peptide V3 has shown anti-angiogenic and anti-tumor effects on $\mathrm{S} 180$ and $\mathrm{H} 22$ xenografts in nude mice. However, the detailed mechanism of action of peptide V3 has not yet been fully elucidated. In the present study, the effects of peptide V3 on the growth of human HCC cells were examined both in vitro and in vivo. Our results showed that peptide $\mathrm{V} 3$ inhibited the proliferation, viability, migration, and invasion of human HCC cells. However, no obvious effect was observed in HL-7702 cells. Peptide V3 increased the apoptosis and decreased the protein levels of H-RAS, phospho (p)-RAF, p-MEK, and p-extracellular signal-regulated protein kinase (ERK) in human HCC cells. Peptide V3 suppressed the growth of human $\mathrm{HCC}$ xenografts by down-regulating angiogenesis and up-regulating apoptosis. In conclusion, peptide V3 could inhibit the growth of human HCC by inhibiting the Ras/Raf/MEK/ERK signaling pathway. Novel peptides and modification strategies could be designed and applied for the treatment of different types of cancer.
\end{abstract}

Key words: peptide V3, HCC, apoptosis, angiogenesis, signaling pathway

\section{Introduction}

Hepatocellular carcinoma (HCC) is now considered one of the leading causes of cancer-related deaths in the world [1-3]. The high mortality rate could reflect the poor prognosis for patients with advanced-stage HCC, the pattern of clinical presentation, and the poor outcome associated with cirrhosis [4]. The high rate of recurrence and heterogeneity are the two major features of HCC [5]. Surgical procedures such as liver transplantation and liver resection are the first-line treatments for HCC [6, 7]. Even after surgical procedures, the overall 5-year survival rate of HCC patients remains very poor because of high recurrence rates [7]. These findings create an immediate demand to better understand the molecular defects responsible for HCC in order to identify novel potential biomarkers and characterize candidate-signaling pathways that can be further used for therapeutic intervention [8].

Angiogenesis, the sprouting of new blood vessels from the pre-existing vasculature, plays a crucial role in the development of solid tumors, which could provide necessary oxygen and nutrients and carry away metabolic wastes [9-11]. It has been shown that many growth factors are involved in 
tumor angiogenesis, such as vascular endothelial growth factor (VEGF), epidermal growth factor (EGF), and angiogenin (Ang) [12-14]. Recently, a number of peptides with anti-tumor effects have been identified and developed [11]. ATWLPPR (V1), a heptapeptide identified from a mutated phage library, possesses anti-angiogenic properties via its binding to neuropilin-1 (NRP-1) and selectively inhibiting VEGF165 binding to NRP-1, which could inhibit tumor growth and angiogenesis [15-17]. NLLMAAS (V2), another heptapeptide selected from a phagedisplayed peptide library, could inhibit the binding of Ang-1 and Ang-2 to immobilized Tie-2 [18]. In our previous study, we have connected two peptides, V1 and V2, which can respectively block the VEGF/ VEGFR-2 and Ang/Tie-2 signal pathway, via a flexible linker, Ala-Ala, to reconstruct a novel peptide, ATWLPPRAANLLMAAS (V3). The anti-angiogenic and anti-tumor effects of peptide V3 are significantly higher than those of peptides V1 and V2 on S180 and H22 xenografts in nude mice [19]. However, whether peptide V3 could inhibit the growth of human HCC cells needs to be further investigated.

In the present study, we detected the effect and mechanism of peptide V3 on the proliferation, migration, and invasion of human HCC cells in vitro. We further examined the effects of peptide V3 on tumor growth and angiogenesis in nude mice bearing human HCC xenografts.

\section{Materials and Methods}

\section{Cell culture}

Normal human liver cell line HL-7702 and human HCC cell lines SMMC-7721 and Huh-7 were purchased from Institute of Biochemistry and Cell Biology, Chinese Academy of Sciences (IBCB, CAS, Shanghai, China) and cultured in high-glucose Dulbecco's modified Eagle's medium (DMEM) supplemented with $10 \%$ fetal bovine serum (FBS), 100 $\mathrm{U} / \mathrm{ml}$ penicillin, and $100 \mu \mathrm{g} / \mathrm{ml}$ streptomycin. Cells were grown in an incubator with a humidified atmosphere of $95 \%$ air and $5 \% \mathrm{CO}_{2}$ at $37^{\circ} \mathrm{C}$. Confluent cells were transferred to serum-free DMEM medium for overnight starvation before each experiment. The cells were divided into five groups: group 1 with phosphate-buffered saline (PBS), group 2 with peptide V1 $(200 \mu \mathrm{M})$, group 3 with peptide V2 (200 $\mu \mathrm{M})$, group 4 with peptide V1+V2 $(200 \mu \mathrm{M})$, and group 5 with peptide V3 $(200 \mu \mathrm{M})$. After $24 \mathrm{~h}$ of treatment, the cells were then used for subsequent experiments.

\section{Cell growth assay}

The 5-ethynyl-2'-deoxyuridine (EdU) incorporation assay was performed using the Cell-Light EdU
Apollo 567 In Vitro Imaging Kit (RiboBio, Guangzhou, Guangdong, China) according to the manufacturer's protocols. Cell proliferation rate $=$ (EdU-positive cells)/(total number of cells) $\times 100 \%$ [20]. The cell viability was detected using the CellTiter $96 \mathrm{AQ}_{\text {ueous }}$ One Solution Cell Proliferation Assay kit (MTS; Promega, Madison, WI, USA) according to the manufacturer's instructions. The cell viability was expressed as a percentage relative to the untreated control cells.

\section{Colony formation assay}

Cells $\left(8 \times 10^{2}\right.$ per well $)$ were seeded in 6-well plates and cultivated in culture medium at $37^{\circ} \mathrm{C}$ for a week. Colonies were washed with PBS for three times before subjected to cell fixation using methanol $(1 \mathrm{ml})$ at room temperature for $15 \mathrm{~min}$. Crystal violet was added into each well and incubated for $30 \mathrm{~min}$ at room temperature. Plates were gently washed with water and air-dried at room temperature. Then, the 6-well plate was scanned for colony counting and analysis.

\section{Wound healing assay}

Confluent cells were scratched using a sterile micropipette tip and washed twice with PBS. The migration distance was photographed under an Olympus CKX41 microscope (Olympus, Tokyo, Japan) and measured using Image J software (National Institute for Health, Bethesda, MD, USA). The migration rate $(\mathrm{MR})$ was calculated as $\mathrm{MR}(\%)=[(\mathrm{A}$ $\mathrm{B}) / \mathrm{A}] \times 100$, where $\mathrm{A}$ is the width at $0 \mathrm{~h}$, and $\mathrm{B}$ is the width at $24 \mathrm{~h}$ [20].

\section{Soft agar assay}

Cells were suspended in $0.6 \%$ agarose and medium supplemented with 10\% FBS, and the mixture was seeded in 6-well plates containing a basal layer of $1.2 \%$ agarose at $1 \times 10^{4}$ cells/well. The medium was replaced every three days. After two weeks of routine culture, colonies were photographed under an Olympus CKX41 microscope. For each well, viable colonies larger than $0.1 \mathrm{~mm}$ in diameter were counted.

\section{Migration and invasion assays}

For migration and invasion assays, $1 \times 10^{5}$ cells were seeded into the upper chamber in serum-free DMEM medium uncoated or coated with Matrigel (BD Biosciences, San Jose, CA, USA). In the lower chamber, $500 \mu \mathrm{l}$ corresponding medium containing $10 \%$ FBS was added. After $24 \mathrm{~h}$ of incubation, the cells were scrubbed with a cotton tip swab, while cells on the bottom surface of the membrane were fixed with $4 \%$ paraformaldehyde at $37^{\circ} \mathrm{C}$ for $20 \mathrm{~min}$ and stained with $0.1 \%$ crystal violet at $37^{\circ} \mathrm{C}$ for $10 \mathrm{~min}$. The cell number was counted with a Zeiss Axioskop 2 plus 
microscope (Carl Zeiss, Thornwood, NY, USA).

\section{TdT-mediated dUTP-biotin nick end labeling (TUNEL) assay}

TUNEL staining was performed using an In Situ Cell Death Detection Kit (Beyotime Biotechnology, Shanghai, China) according to the manufacturer's protocols. Cells were observed under a fluorescent microscope (Eclipse Ti, Nikon, Melville, NY, USA). The percentage of TUNEL-positive cells was calculated using the formula: Apoptotic index = (TUNEL-positive cells)/(total number of cells) $\times 100 \%$ [21].

\section{Western blotting}

Total protein was extracted from SMMC-7721 and Huh-7 cells. Western blotting was performed to detect the expression levels of target proteins. The primary antibodies, including anti-H-RAS, anti-RAF, anti-phospho (p)-c-Raf (Ser259), anti-MEK1/2, antip-MEK1/2 (Ser217/221), anti-extracellular signalregulated protein kinase 1/2 (ERK1/2), and anti-pERK1/2 (Thr202/Tyr204) antibodies were purchased from Cell Signaling Technology (CST, Danvers, MA, USA). Anti-B-cell lymphoma-2 (Bcl-2), anti-Bcl-2associated $\mathrm{X}$ protein (Bax), anti-B-cell lymphomaextra large (Bcl-xl), anti-Bcl-xl/Bcl-2-associated death promoter (Bad), anti-cleaved caspase-3, anti-cleaved caspase-8, anti-cleaved caspase-9, anti-cleaved poly adenosine diphosphate-ribose polymerase (PARP), and anti-glyceraldehyde-3-phosphate dehydrogenase (GAPDH) antibodies were purchased from ProteinTech (Chicago, IL, USA). The horseradish peroxidase-conjugated secondary antibody was purchased from CST. The results were normalized to the level of GAPDH. The reaction was visualized using an enhanced chemiluminescence system (Thermo Fisher Scientific, Rockford, IL, USA). The bands were semi-quantified with Image J software.

\section{Animal study}

Animal experiments were approved by the Committee of Medical Ethics and Welfare for Experimental Animals of Henan University School of Medicine (HUSOM-2015-008) in compliance with the Experimental Animal Regulations formulated by the National Science and Technology Commission, China. Animal studies were conducted as previously described with slight modifications [22]. Sixty BALB/C nude mice (4-week-old, male, $\mathrm{n}=6$ per group) were purchased from Beijing HFK Bioscience Co., Ltd. (Certificate No. SCXK (Jing) 2014-0004, Beijing, China). SMMC-7721 and Huh-7 cells $\left(5 \times 10^{6}\right.$ cells in $200 \mu$ PBS) were implanted by subcutaneous injection into the right flanks of mice. Twenty-four hours after inoculation, thirty mice with SMMC-7721 or Huh-7 cells were randomly divided into 5 groups, respectively. Peptides (dissolved in normal saline) were administrated subcutaneously (near the implanted tumor) for four weeks $(0.1 \mathrm{ml} / 10 \mathrm{~g})$ : group 1 with normal saline (control), group 2 with peptide V1 $(200 \mu \mathrm{g} / \mathrm{kg} /$ day), group 3 with peptide V2 (200 $\mu \mathrm{g} / \mathrm{kg} /$ day), group 4 with peptide V1 + V2 (200 $\mu \mathrm{g} / \mathrm{kg} /$ day), and group 5 with peptide V3 (200 $\mu \mathrm{g} / \mathrm{kg} /$ day). Tumor volumes and body weighs were measured daily during the experiment. The tumor volumes were calculated as volume $=\mathrm{L} \times \mathrm{W}^{2} / 2$, where $\mathrm{L}$ is the longest dimension parallel to the skin surface and $\mathrm{W}$ is the dimension perpendicular to $\mathrm{L}$ and parallel to the surface [23]. The tumor volume doubling time (TVDT) was calculated according to the formula: $\mathrm{TVDT}=\left(\mathrm{T}-\mathrm{T}_{0}\right) \times \log 2 / \log (\mathrm{V} 2 / \mathrm{V} 1)$, where $(\mathrm{T}$ - $\mathrm{T}_{0}$ ) represents the time interval and V2 and V1 indicate the volumes of tumor at the two measurement times [24]. At the end of the experiment, mice were sacrificed and tumors were excised and weighted to measure the inhibition rate (IR). The IR of tumor growth was calculated as $\operatorname{IR}(\%)=[(\mathrm{A}-\mathrm{B}) / \mathrm{A}] \times$ 100 , where $A$ is the average tumor weight of the control group, and B is that of the treatment group [19].

\section{Hematoxylin and eosin (HE) staining}

After sacrifice, a necropsy examination was immediately performed. Tumor samples were fixed in $10 \%$ neutral buffered formalin, embedded in paraffin, sectioned at $5 \mu \mathrm{m}$ thickness, and processed according to the HE staining protocols. Tumor tissues were observed using a Zeiss Axioskop 2 plus microscope.

\section{Immunohistochemistry (IHC) and evaluation}

Tumor tissues were stained with anti-Ki67 antibody (CST, Danvers, MA, USA), followed by incubation with the secondary antibody. Ki67-positive tumor cells were photographed using a Zeiss Axioskop 2 plus microscope. The proliferation index (PI) was calculated by the number of Ki67 positive cells among the total number of resting cells [25]. Cluster of differentiation 31 (CD31) is an ideal biomarker for vascular endothelial cells, and the immunostaining density is represented by the tumor microvessel density (MVD) [26]. Tumor tissues were stained by IHC using CD31 antibody (CST, Danvers, MA, USA) to determine the tumor MVD. Stained vessels with a clearly defined lumen or well-defined linear vessel shape were photographed and counted [22]. In addition, tumor tissues were stained with cleaved-caspase- 3 antibody (ProteinTech, Chicago, IL, USA) to detect the apoptotic index of human HCC xenograft tumors. Apoptotic index was calculated as cleaved caspase 3 positive cells/total cells [27]. 


\section{Statistical analysis}

Data are presented as means \pm standard error of the mean (SEM). The differences between multiple groups were analyzed by one-way analysis of variance using SPSS 17.0 software, followed by Tukey's test. A $P$ value of less than 0.05 was considered to be statistically significant.

\section{Results}

\section{Peptide V3 attenuates the growth, migration, and invasion of human HCC cells}

As shown in Figure 1A-C, the proliferation and viability of SMMC-7721 and Huh-7 cells in V1+V2 group were decreased compared with V1 and V2 group. Furthermore, the proliferation and viability of human HCC cells in V3 group were remarkably lower than those in V1, V2, and V1+V2 group. However, there was no obvious change between each group in HL-7702 cells. In the scratch migration assay, the migration capabilities of human HCC cells were inhibited in V1+V2 group compared with those observed in V1 and V2 group. Peptide V3 showed more potent inhibitory effects on the migration capabilities of human HCC cells than those in V1, V2, and $\mathrm{V} 1+\mathrm{V} 2$ group (Figure 2A and $\mathrm{C}$ ). In addition, peptide V3 dose-dependently inhibited the migration capabilities of human HCC cells, whereas no obvious effect was observed in HL-7702 cells (Figure 2B and D).

In the colony formation assay, compared with V1 and V2 group, the number of colonies was lower in $\mathrm{V} 1+\mathrm{V} 2$ group. Peptide V3 exhibited more potent inhibitory effects on the colony formation capabilities of human HCC cells than those in V1, V2, and V1+V2 group (Figure $3 \mathrm{~A}$ and $\mathrm{B}$ ). In addition, a similar trend was observed in the soft agar assay (Figure 3C and D). Transwell analysis showed that the migration and invasion capacities of human HCC cells were decreased in V1+V2 group when compared with V1 and V2 group. Peptide V3 showed more potent inhibitory effects on the migration and invasion capacities of human HCC cells than peptides V1, V2, and V1+V2 (Figure 3E-H). These results together suggest that peptide $\mathrm{V} 3$ could significantly inhibit the growth, migration, and invasion of human HCC cells.

\section{Peptide V3 increases apoptosis of human HCC cells}

As shown in Figure $4 \mathrm{~A}$ and $\mathrm{B}$, the apoptotic index increased in $\mathrm{V} 1+\mathrm{V} 2$ group compared with $\mathrm{V} 1$ and V2 group. The apoptotic index in V3 group was higher than that in $\mathrm{V} 1, \mathrm{~V} 2$, and $\mathrm{V} 1+\mathrm{V} 2$ group. The protein levels of cleaved caspase-3, 8, 9, and cleaved PARP in human HCC cells showed similar trends
(Figure 4C-E). The ratio between Bad and Bcl-xl and the ratio between Bax and Bcl-2 are important factors in the regulation of apoptosis. Increased Bax/Bcl-2 and $\mathrm{Bad} / \mathrm{Bcl}-\mathrm{xl}$ ratios are common phenomena in mitochondrial-mediated apoptosis in mammalian cells [28, 29]. The Bax/Bcl-2 and Bad/Bcl-xl ratios were increased in $\mathrm{V} 1+\mathrm{V} 2$ group compared with $\mathrm{V} 1$ and V2 group. In addition, the Bax/Bcl-2 and $\mathrm{Bad} / \mathrm{Bcl}-\mathrm{xl}$ ratios in V3 group were higher than those in V1, V2, and V1+V2 group (Figure 5). These results indicate that peptide V3 could induce mitochondrialmediated apoptosis in human HCC cells.

\section{Peptide V3 represses the Ras/Raf/MEK/ERK pathway in human HCC cells}

The Ras/Raf/MEK/ERK cascade is an important intracellular signaling pathway that regulates different types of cellular functions including survival, proliferation, apoptosis, differentiation, motility, and metabolism [30,31]. Deregulation of the RAS/ RAF/MEK/ERK signaling cascade has been considered a hallmark for driving tumorigenesis in different types of human cancers $[32,33]$. As shown in Figure 6, the protein levels of H-RAS, p-RAF, p-MEK, and $\mathrm{p}$-ERK were decreased in $\mathrm{V} 1+\mathrm{V} 2$ group compared with V1 and V2 group. Furthermore, the expression levels of these proteins in V3 group were lower than those in V1, V2, and V1+V2 group. The results show that peptide V3 could suppress the RAS/RAF/ MEK/ERK signaling pathway in human HCC cells.

\section{Peptide V3 inhibits the growth and angiogenesis and increases apoptosis of human HCC xenograft tumors in nude mice}

SMMC-7721 and Huh-7 cells have been widely applied to establish mouse tumor models in cancer research $[22,34,35]$. We therefore investigated the effect of peptide V3 on HCC xenograft growth in BALB/c nude mice. Compared with V1 group, V3 group reduced the tumor volume and increased the tumor doubling time in SMMC-7721 cells. The tumor volume was reduced and the tumor doubling time was increased in V3 group when compared with V1, $\mathrm{V} 2$, and V1+V2 group in Huh-7 cells (Figure 7A and B). Compared with V1 and V2 group, the tumor weight was decreased and the tumor inhibitory rate was increased in V1+V2 group. In V3 group, the tumor weight was lower and the tumor inhibitory rate was higher than those in V1, V2, and V1+V2 group (Figure 7C and D). As shown in Figure 7E, no obvious change was observed in the body weight among each group. However, the body weight change in $\mathrm{V} 1+\mathrm{V} 2$ group was significantly lower than that in the control group (Figure $7 F$ ), suggesting that there was a slight toxicity in $\mathrm{V} 1+\mathrm{V} 2$ group. 
a


HL-7702

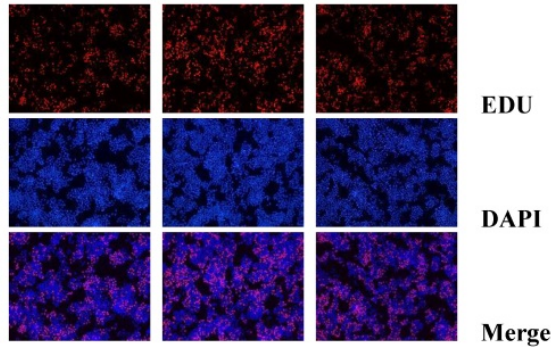

SMMC-7721


EDU



Huh-7


V1



$\mathbf{V} 1+\mathrm{V} 2$


V2
SMMC-7721
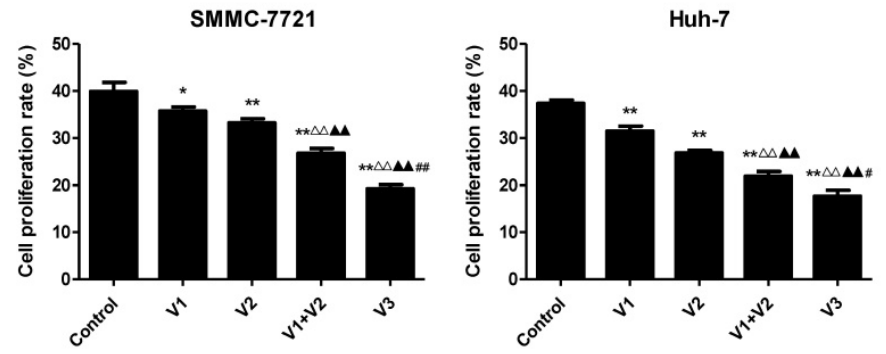

c


Figure 1. Effects of peptide V3 on the proliferation and viability of normal human liver cells and human HCC cells. (A) DNA replication activities of HL-7702, SMMC-7721, and Huh-7 cells in each group were examined by EdU assay; original magnification $100 \times$. (B) The proliferation rate of each group was analyzed according to the formula: Cell proliferation rate $=($ EdU-positive cells $) /($ total number of cells $) \times 100 \%[20]$. (C) The percentages of viable cells were determined using MTS assay and the cell viability of the control group was taken as $100 \%$. Data are presented as mean \pm SEM of three independent experiments; $* P<0.05, * * P<0.01$ compared with the control group; $\triangle \triangle P<0.01$ compared with $\mathrm{V} 1$ group; ${ }^{\boldsymbol{\Lambda}} \mathrm{P}<0.01$ compared with $\mathrm{V} 2$ group; $\# P<0.05$, \#P $<0.01$ compared with $\mathrm{V} 1+\mathrm{V} 2$ group. 
a


HL-7702

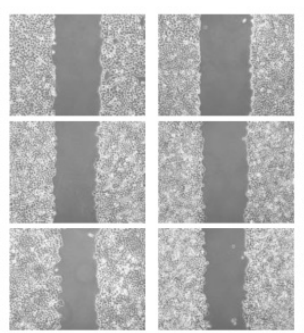

SMMC-7721
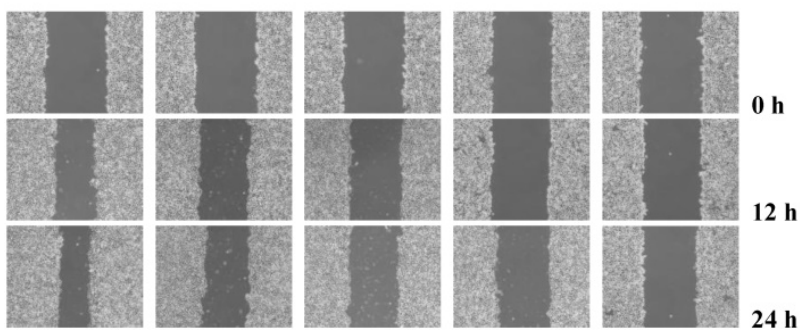

Huh-7



Control



V1



V2



$\mathrm{V} 1+\mathrm{V} 2$



V3 b
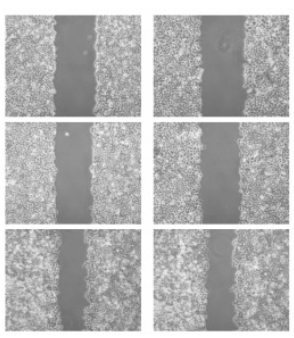

HL-7702

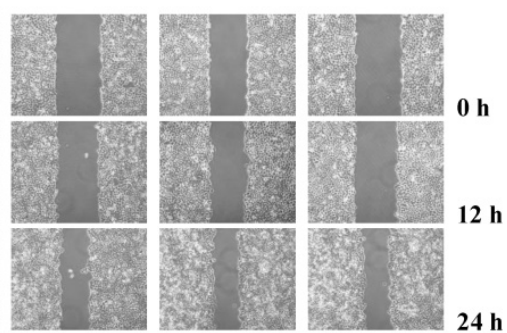

SMMC-7721
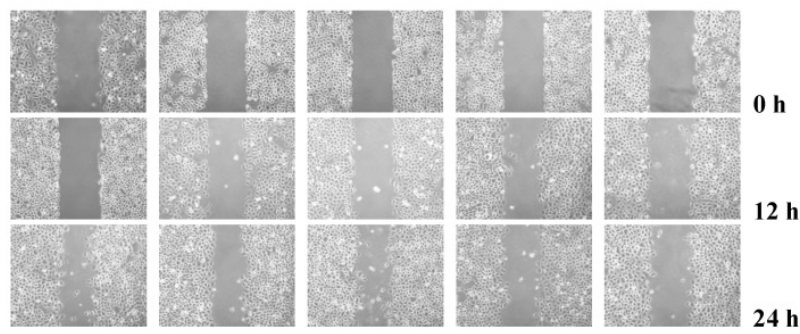

Huh-7


25



50


100

200

V3 $(\mu \mathrm{M})$

c
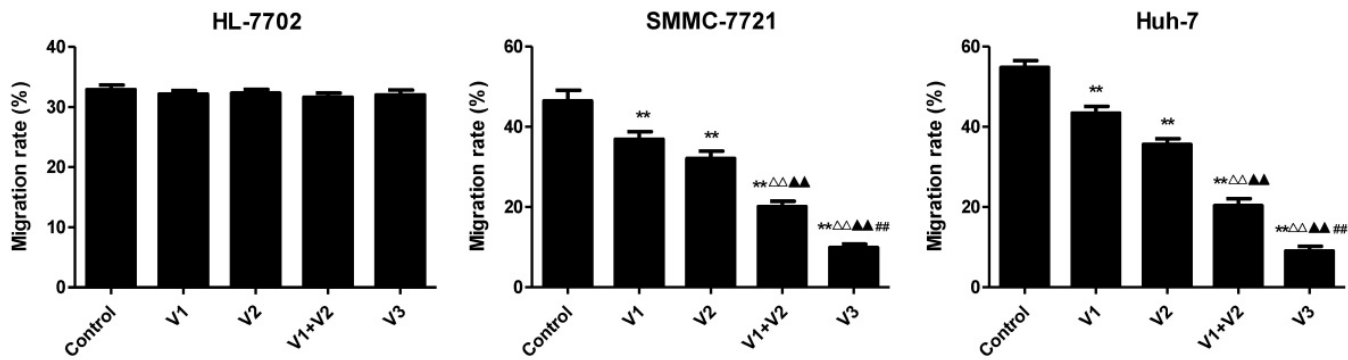

d


Figure 2. Effects of peptide $\mathbf{V} 3$ on the migration of normal human liver cells and human $\mathrm{HCC}$ cells. (A) Effects of peptides $\mathrm{V} 1, \mathrm{~V} 2, \mathrm{~V} 1+\mathrm{V} 2$, and $\mathrm{V} 3$ on the cell migration were measured by wound healing assay; original magnification $100 \times$. (B) Effects of $25,50,100$, and $200 \mu \mathrm{M}$ peptide $\mathrm{V} 3$ on the cell migration were measured by wound healing assay; original magnification $100 \times$. (C, D) The MR of normal human liver cells and human HCC cells were calculated by the formula: MR $(\%)=[(A-B) / A] \times 100$, where $A$ is the width at $0 \mathrm{~h}$, and $B$ is the width at $24 \mathrm{~h}$ [20]. Data are presented as mean \pm SEM of three independent experiments; $* P<0.05, * * P<0.01$ compared with the control group; $\Delta \triangle P<0.01$ compared with $\mathrm{V} 1$ group; ${ }^{\boldsymbol{\Lambda}}{ }^{2} P<0.01$ compared with $\mathrm{V} 2$ group; $\# \mathrm{P}<0.01$ compared with $\mathrm{V} 1+\mathrm{V} 2$ group. 
a
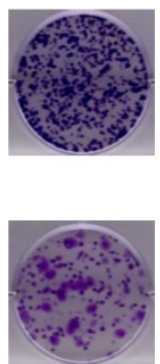

Control

c
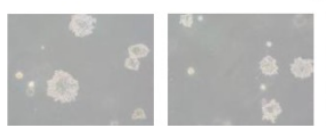

MC-772

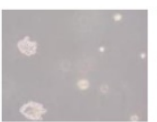

Huh-7

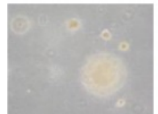

Control

e
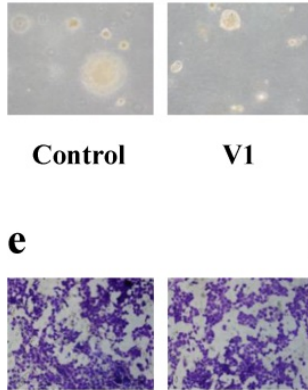

V1

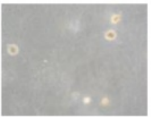

V2

SMMC-7721


Huh-7
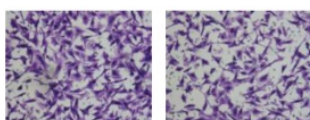

V1

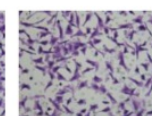

V2
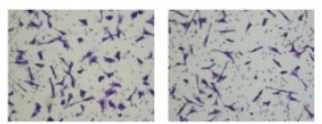

V3 b
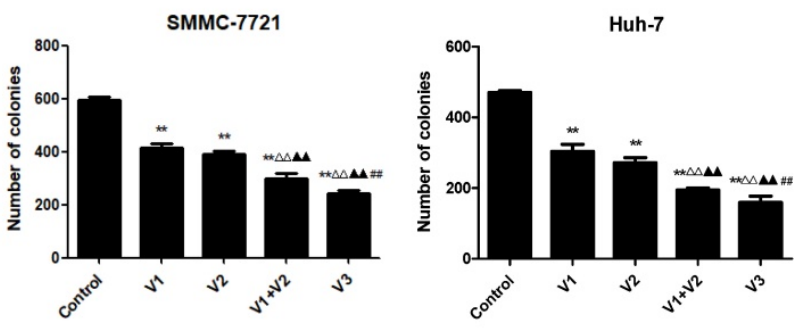

d
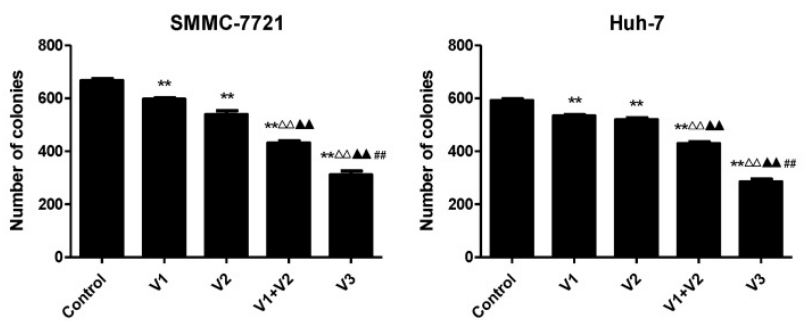

f

SMMC-7721

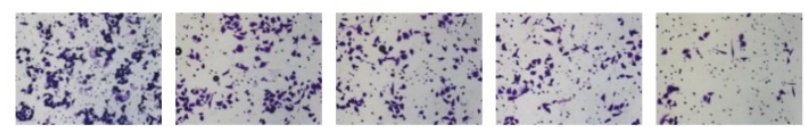

Huh-7

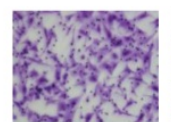

Control

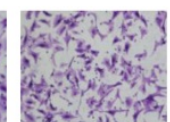

V1

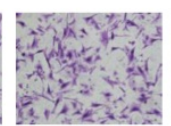

V2

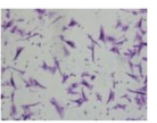

$\mathrm{V} 1+\mathrm{V} 2$

V3

h
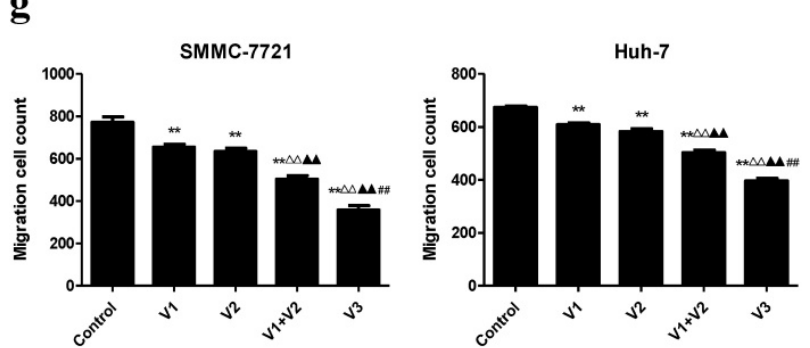

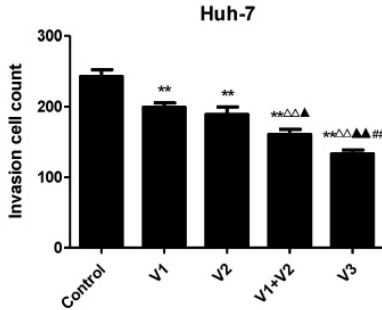

Figure 3. Effects of peptide V3 on the clonogenic capacity, migration and invasion of human HCC cells. (A) Colony formation assay was used to determine the clonogenic capacity of SMMC-7721 and Huh-7 cells; original magnification $100 \times$. (B) The numbers of colonies were calculated. (C) Soft agar assay was performed to examine the anchorage-independent survival of cells; original magnification $100 \times$. (D) The number of colonies was calculated. (E) Transwell assay was performed to assess the migration of SMMC-7721 and Huh-7 cells; original magnification $200 \times$. (F) Transwell assay was performed to assess the invasion of SMMC-7721 and Huh-7 cells; original magnification $200 \times$. (G) The numbers of the migrated cells were calculated. $(\mathrm{H})$ The numbers of the invasive cells were calculated. Data are presented as mean \pm SEM of three independent experiments; $* * P<0.01$ compared with the control group; $\triangle \triangle P<0.01$ compared with $V 1$ group; ${ }^{\mathbf{A}} P<0.05,{ }^{\wedge} P<0.01$ compared with $\mathrm{V} 2$ group; ${ }^{\prime \prime} P<0.01$ compared with $\mathrm{V} 1+\mathrm{V} 2$ group. 


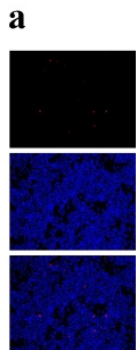

Control

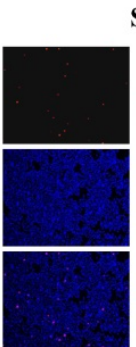

V1
SMMC-7721

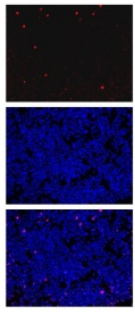

V2

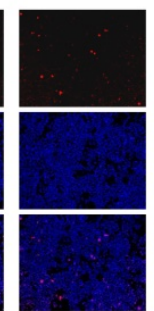

$\mathrm{V} 1+\mathrm{V} 2$

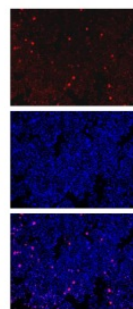

V3

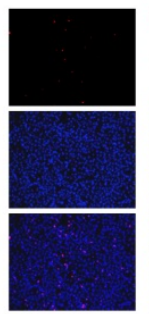

Control

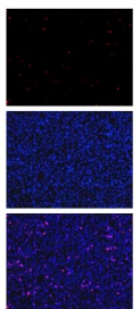

V1
Huh-7

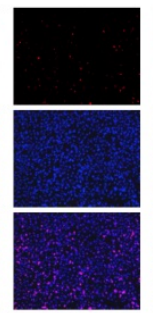

V2

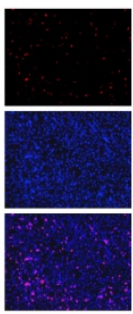

$\mathrm{V} 1+\mathrm{V} 2$
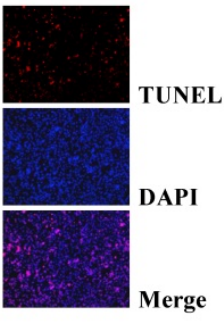

V3

b
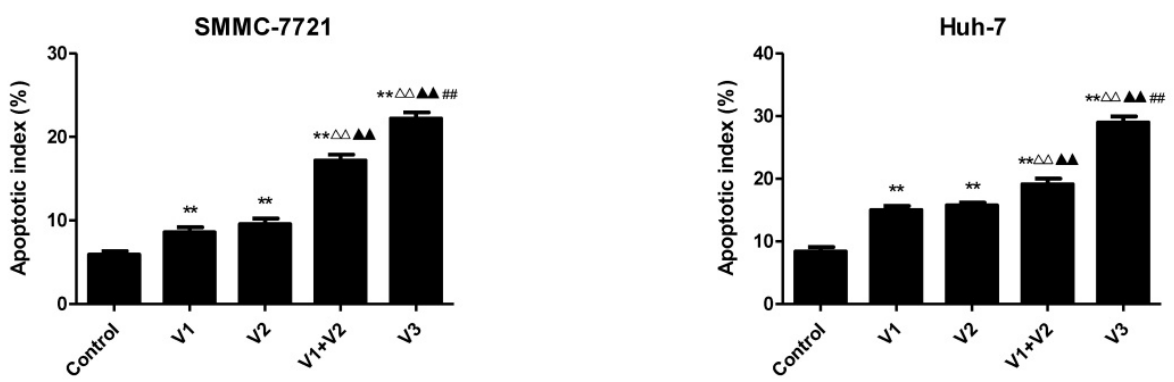

c

SMMC-7721
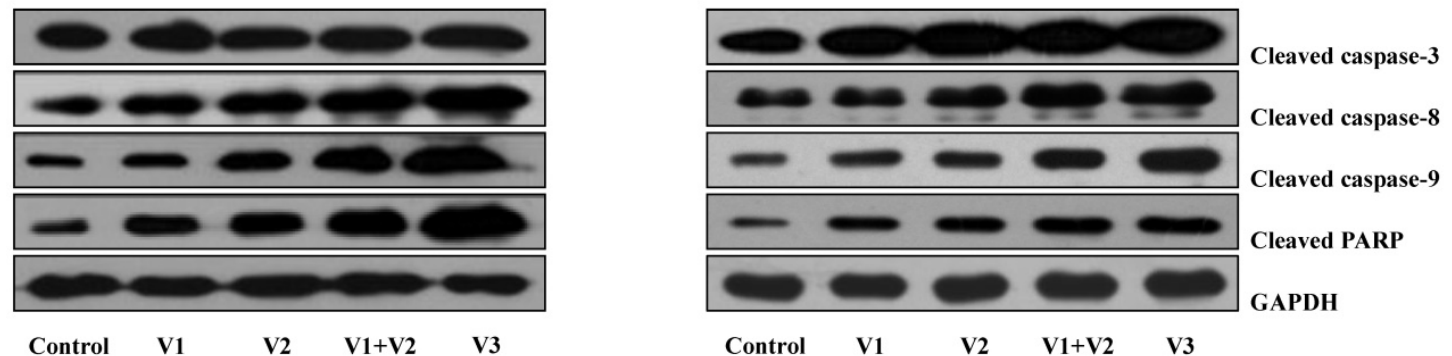

d
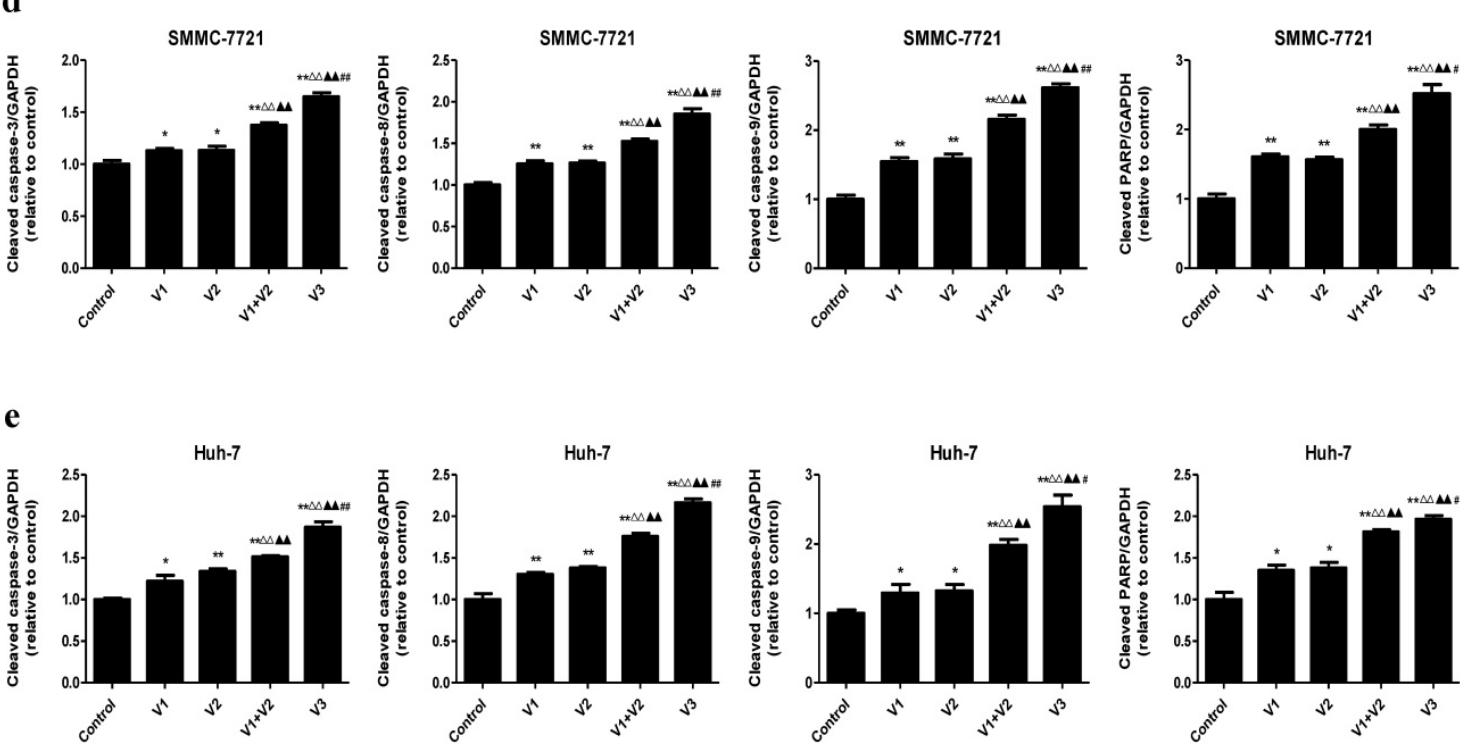

Figure 4. Effects of peptide $\mathbf{V} 3$ on the apoptosis of human HCC cells. (A) The apoptotic levels of SMMC-7721 and Huh-7 cells were measured by TUNEL staining; original magnification 100x. (B) The percentage of TUNEL-positive cells was calculated using the formula: Apoptotic index $=($ TUNEL-positive cells)/(total number of cells) $\times 100 \%$ [21]. (C) Western blotting analysis for the expression of cleaved caspase-3, -8, -9, and cleaved PARP in SMMC-7721 and Huh-7 cells. GAPDH was used as the loading control. (D, E) The densitometry analysis of each factor was performed in SMMC-7721 and Huh-7 cells, normalized to the corresponding GAPDH level. Data are presented as mean \pm SEM of three independent experiments; $* P<0.05$, $* * P<0.01$ compared with the control group; $\triangle \triangle P<0.01$ compared with $V 1$ group; ${ }^{\boldsymbol{\Lambda}} P<0.01$ compared with $\mathrm{V} 2$ group; $\# P$ $<0.05, \ldots P<0.01$ compared with $\mathrm{V} 1+\mathrm{V} 2$ group. 
a

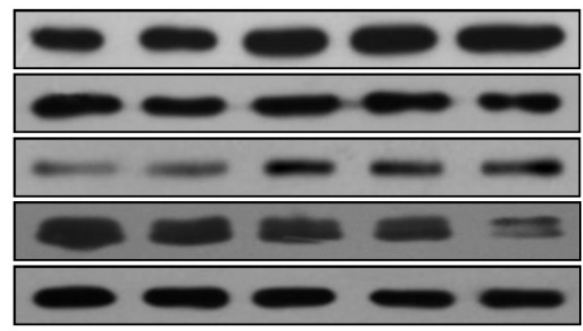

$\begin{array}{lllll}\text { Control } & \text { V1 } & \text { V2 } & \text { V1+V2 } & \text { V3 }\end{array}$
Huh-7

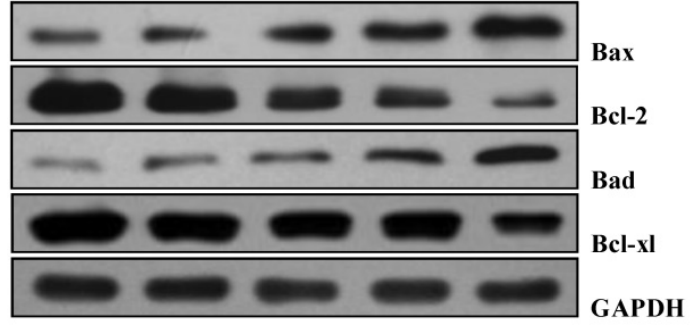

$\begin{array}{lllll}\text { Control } & \text { V1 } & \text { V2 } & \text { V1 }+ \text { V2 } & \text { V3 }\end{array}$

b
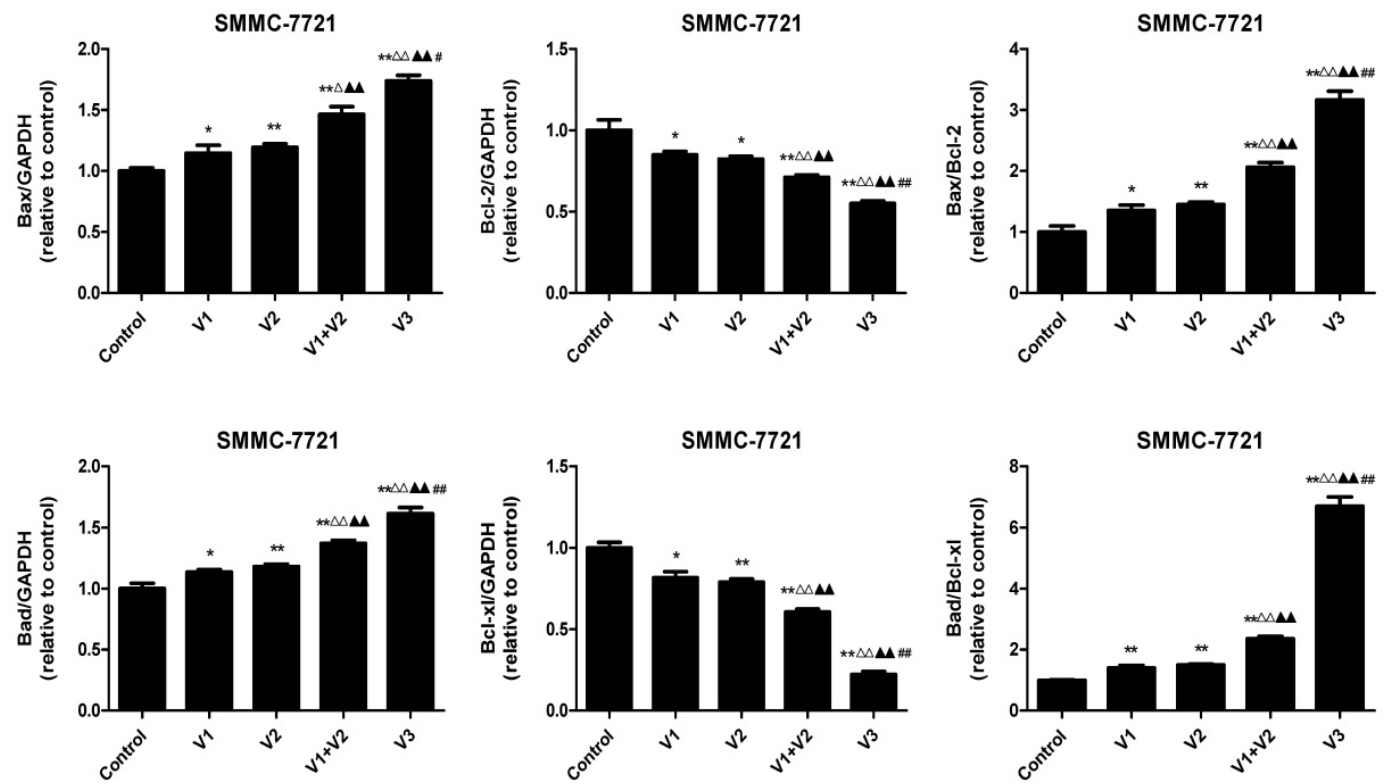

c
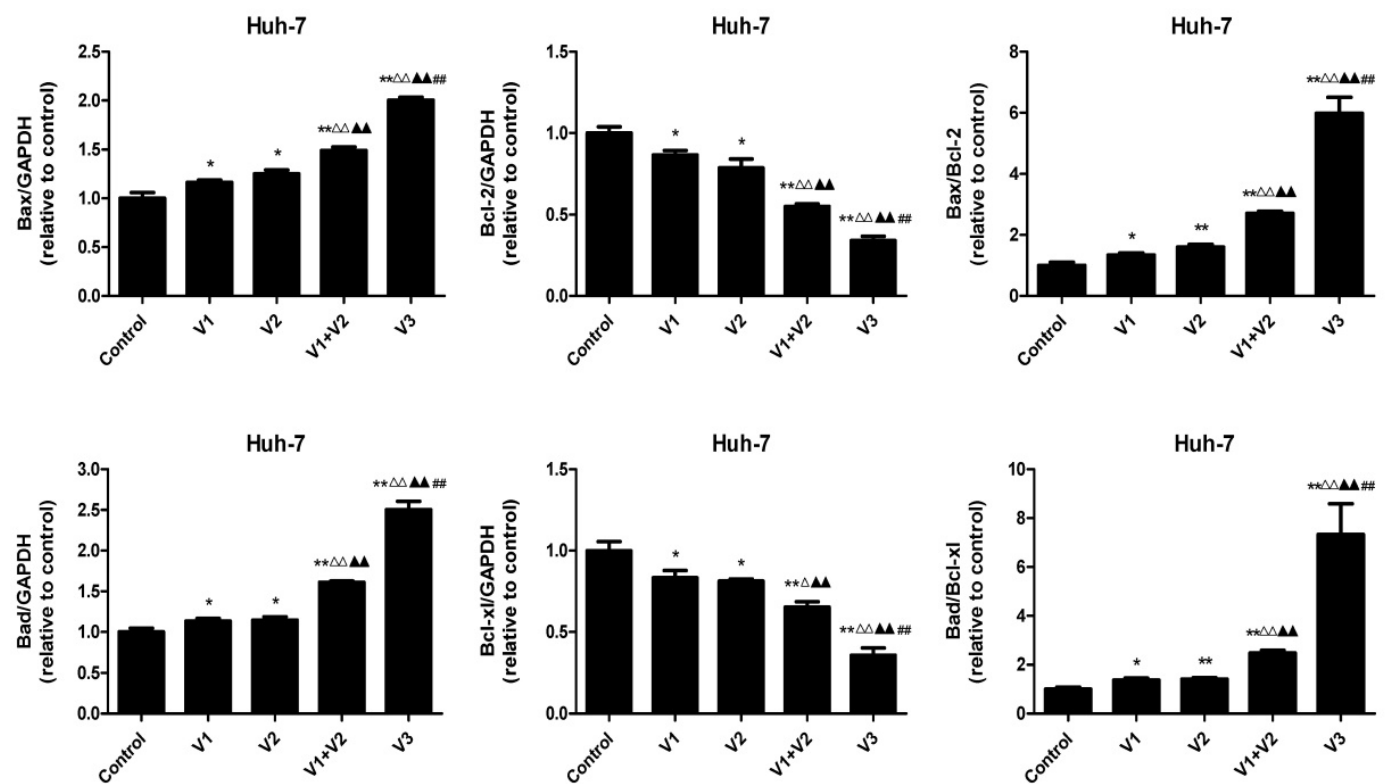

Figure 5. Effects of peptide $\mathbf{V} 3$ on the expressions of Bcl-2 family proteins in human $\mathbf{H C C}$ cells. (A) Western blotting analysis of the expressions of Bax, Bcl-2, Bad, and $\mathrm{Bcl}-\mathrm{xl}$ in SMMC-7721 and Huh-7 cells. GAPDH was used as the loading control. (B, C) The densitometry analysis of each factor was performed, normalized to the corresponding GAPDH level. The expression ratios of $\mathrm{Bax} / \mathrm{Bcl}-2$ and $\mathrm{Bad} / \mathrm{Bcl}-\mathrm{xL}$ were quantified. Data are presented as mean $\pm \mathrm{SEM}$ of three independent experiments; $* P<0.05$, $* * P<0.01$ compared with the control group; $\Delta P<0.05, \triangle \Delta P<0.01$ compared with $\mathrm{V} 1$ group; ${ }^{\Delta}{ }^{\wedge}<0.01$ compared with $\mathrm{V} 2$ group; $\# P<0.05$, \#P<0.01 compared with $\mathrm{V} 1+\mathrm{V} 2$ group. 
$\mathbf{a}$

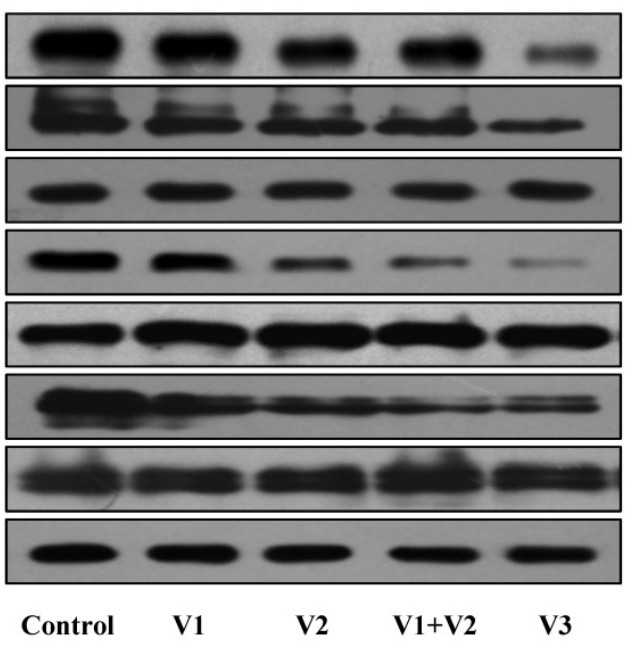

SMMC-7721

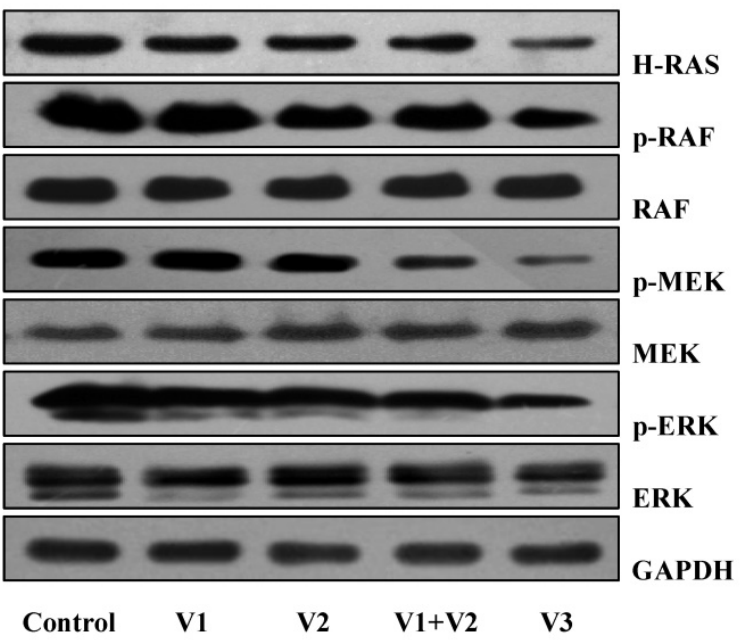

b
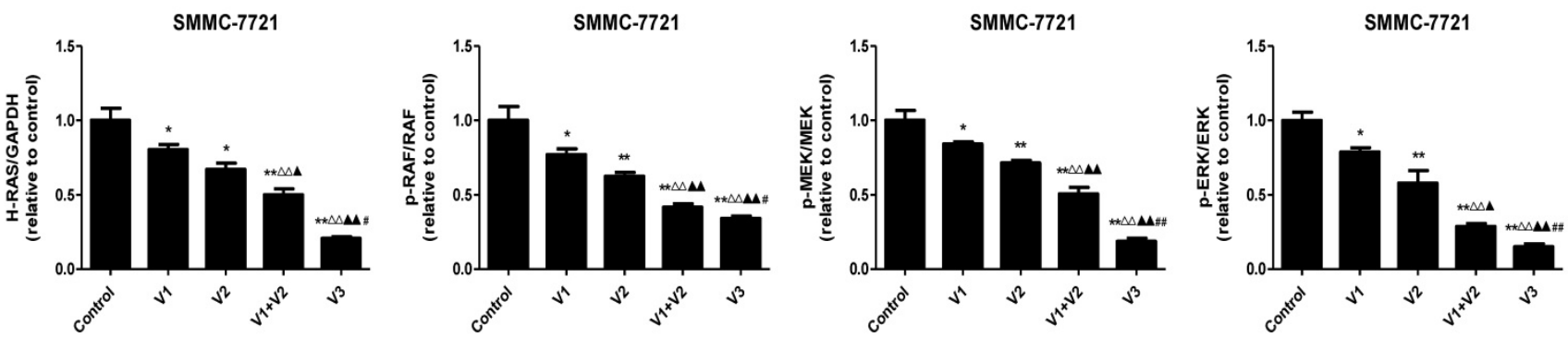

c
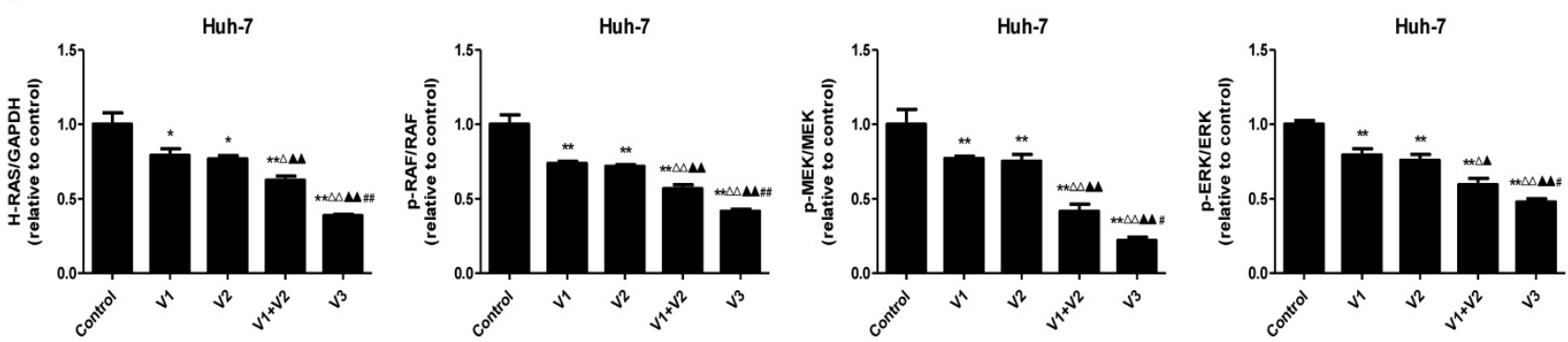

Figure 6. Peptide V3 suppresses the Ras/Raf/MEK/ERK signaling pathway in human HCC cells. (A) Western blotting analysis of the expressions of $H$-RAS, RAF, P-RAF, MEK, p-MEK, ERK, p-ERK in SMMC-7721 and Huh-7 cells. GAPDH was used as the loading control. (B, C) The intensities of the bands were quantified by densitometry analyses and normalized by the amount of GAPDH, RAF, MEK 1/2, and ERK 1/2, respectively. Data are presented as mean $\pm S E M$ of three independent experiments; $* P<0.05$, ** $P$ $<0.01$ compared with the control group; $\triangle P<0.05, \triangle \triangle P<0.01$ compared with $\vee 1$ group; $P<0.05,{ }^{\Delta \Lambda} P<0.01$ compared with $V 2$ group; $\# P<0.05$, \#P<0.01 compared with $\mathrm{V} 1+\mathrm{V} 2$ group.

IHC with the Ki67 antibody confirmed that the in vivo proliferation of human HCC cells was inhibited in V1+V2 group compared with V1 and V2 group. The proliferation index was lower in $\mathrm{V} 3$ group than those in $\mathrm{V} 1, \mathrm{~V} 2$, and $\mathrm{V} 1+\mathrm{V} 2$ group. The protein expression of CD31 in human HCC xenograft tumors exhibited a similar trend. However, the apoptotic index was increased in V1+V2 group compared with V1 and V2 group. In addition, the apoptotic index in V3 group was higher than that in V1, V2, and V1+V2 group
(Figure 8). These results together indicate that peptide V3 could effectively inhibit the growth and angiogenesis and increase apoptosis of human HCC xenograft tumors.

\section{Discussion}

Our previous study showed that the anti-angiogenic and anti-tumor effects of peptide V3 were significantly higher than those of peptides V1 and V2 on both S180 and H22 xenografts in nude 
mice, however the mechanism of action of peptide V3 has not been fully elucidated [19]. HCC is one of the leading causes of cancer-related deaths in the world [1-3]. The human HCC cells lines SMMC-7721 and Huh-7 cells have been widely implicated in establishing tumor-bearing animal models [22, 34, 35]. In the present study, SMMC-7721 and Huh-7 cells were used to evaluate the effects of peptide V3 both in vitro and in vivo. The results demonstrated that peptide V3 showed more potent inhibitory effects than peptides V1 and V2 on decreasing the proliferation and viability, as well as inhibiting the migration and invasion capabilities of human HCC cells. However, no obvious effect was observed in HL-7702 cells. These results suggest that peptide V3 could play an important role in attenuating the growth, migration, and invasion of human HCC cells.

Apoptosis, also known as programmed cell death, plays a critical role in the normal development and maintenance of tissue homeostasis in multicell-

a
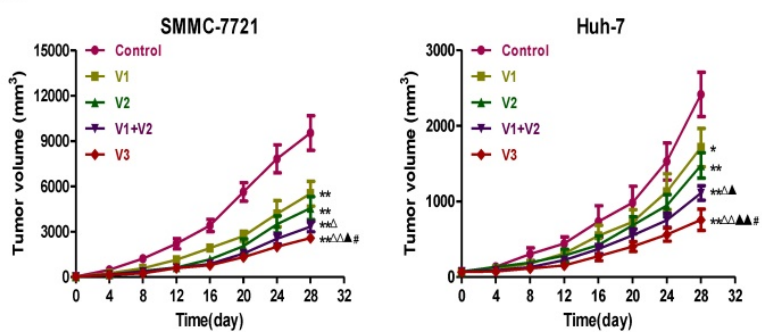

c
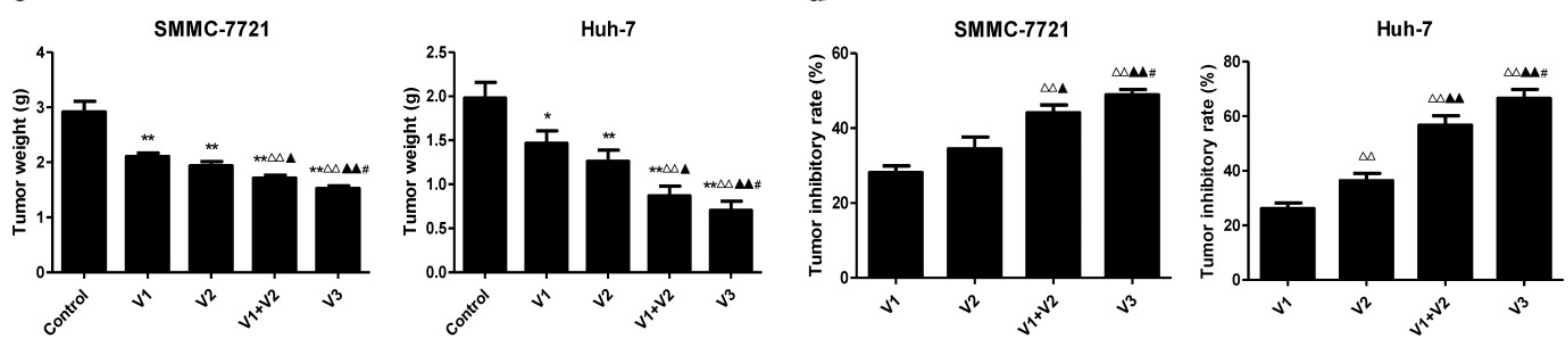

e

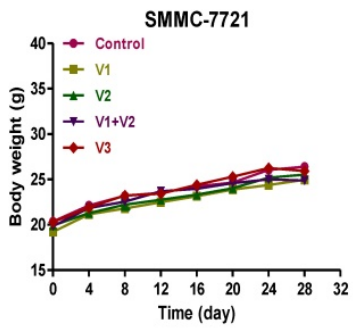

ular organisms [36]. There are two major apoptotic signaling pathways: an intrinsic pathway that occurs through the mitochondria and an extrinsic pathway initiated by death receptors [11]. The proteins of the Bcl-2 family are important regulators of apoptosis in mammals, such as Bax, Bcl-2, Bad, and Bcl-xl [37]. Caspases can be activated in response to a variety of apoptotic stimuli and active caspase-3 could inactivate PARP, thus leading to the occurrence of apoptotic cascade [38]. Bovine lactoferricin, a cationic antimicrobial peptide, has potent anticancer activity by inducing apoptosis in many human cancer cells $[39,40]$. Similarly, our results showed that peptide V3 remarkably increased the apoptotic index, protein expressions of cleaved caspase-3, 8, 9, cleaved PARP, as well as Bax/Bcl-2 and Bad/Bcl-xl ratios, suggesting the activation of mitochondria-mediated pathway. In sum, these results demonstrate that peptide V3 could induce mitochondrial-mediated apoptosis in human HCC cells.

b

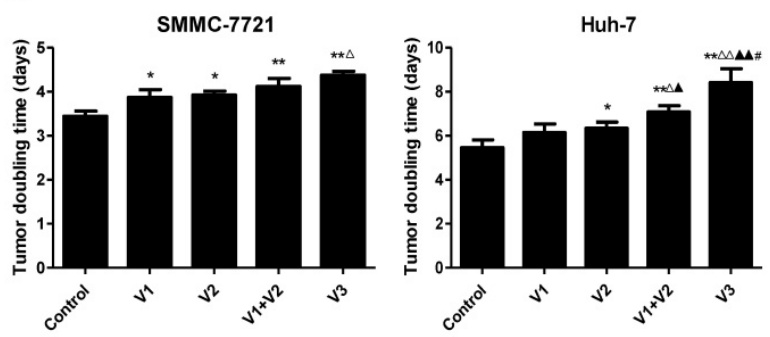

f
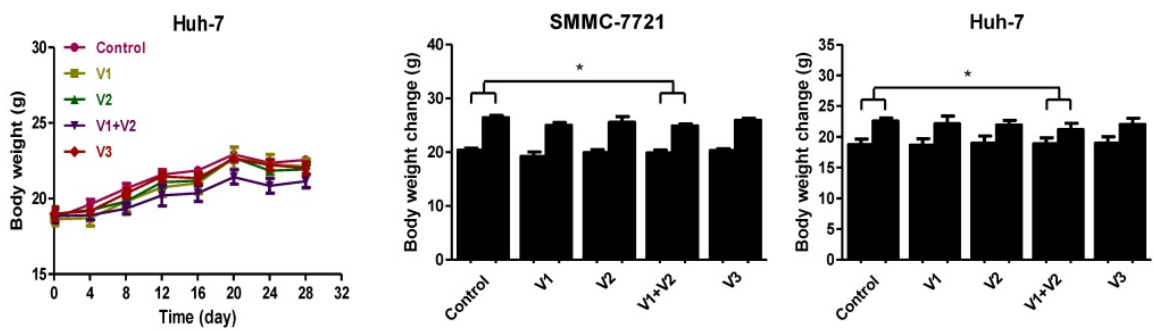

Figure 7. Effects of peptide V3 on the growth of SMMC-7721 and Huh-7 xenograft tumors in nude mice. (A, B) The tumor volume of each group was measured every day and the TVDT was calculated by the formula: TVDT $=\left(T-T_{0}\right) \times \log 2 / \log (V 2 / V 1)$, where $\left(T-T_{0}\right)$ represents the time interval and $V 2$ and $V 1$ indicate the volumes of tumor at the two measurement times [24]. (C, D) The tumors were weighed and the IR of tumor growth were calculated by the formula: IR $(\%)=[(A-B) / A] \times 100$, where $A$ is the average tumor weight of the control group, and $B$ is that of the treatment group [19]. (E, F) The body weight change curve of each group during the experiment and the body weight of each group on the first day (day 0 ) and the last day (day 28). Values are presented as mean \pm SEM $(n=6) ; * P<0.05$, $* * P<0.01$ compared with the control group; $\triangle P<0.05, \triangle \Delta P<0.01$ compared with $V 1$ group; ${ }^{\Delta} P<0.05,{ }^{\Delta}{ }^{\Delta} P<0.01$ compared with $V 2$ group; $\# P<0.05$ compared with $V 1+V 2$ group. 
a

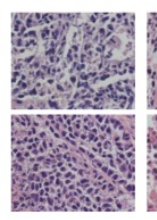

Control

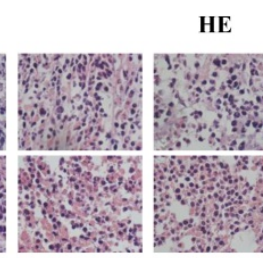

V2

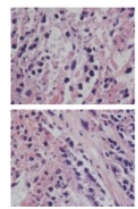

V1+V2

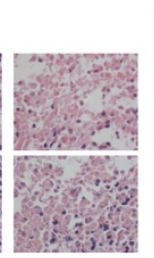

V3 b

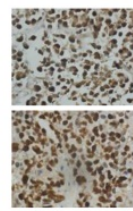

Control

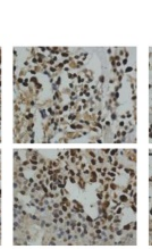

V1
Ki67

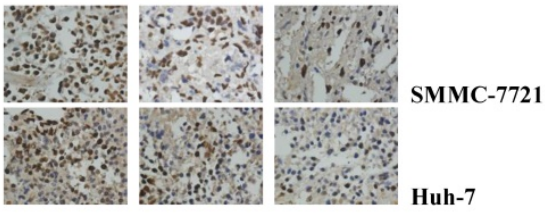

V2

$\mathbf{V} 1+\mathrm{V} 2$

V3

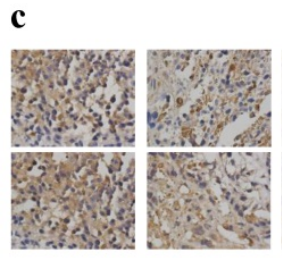

Control
CD31

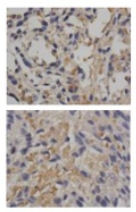

V2

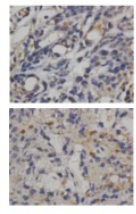

$\mathrm{V} 1+\mathrm{V} 2$

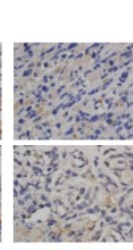

V3 d

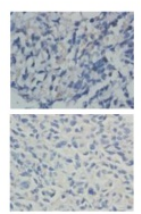

Control

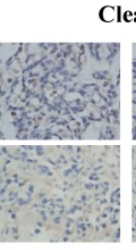

V1
Cleaved caspase-3

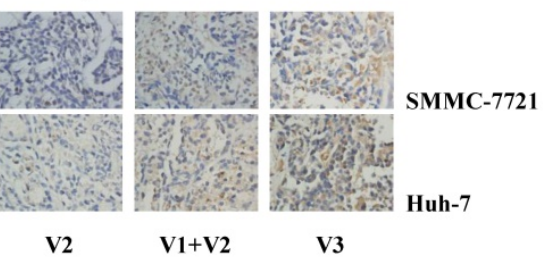

e

SMMC-7721

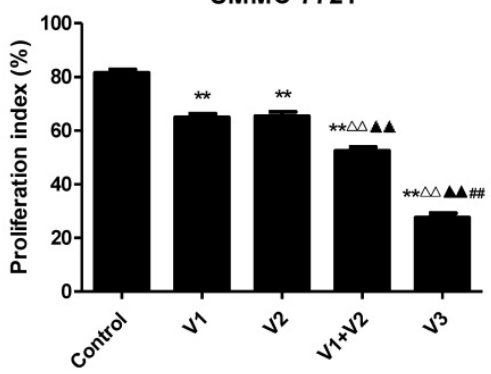

f

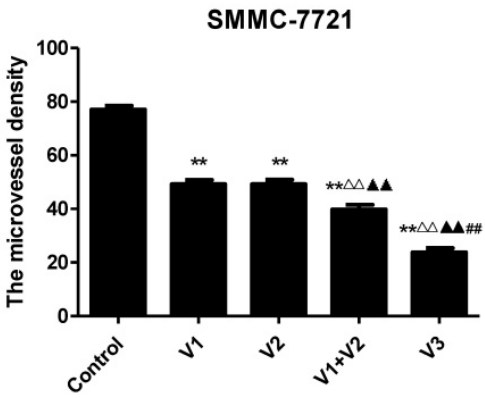

g

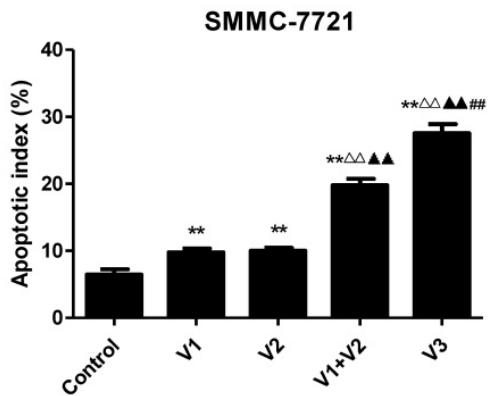

Huh-7

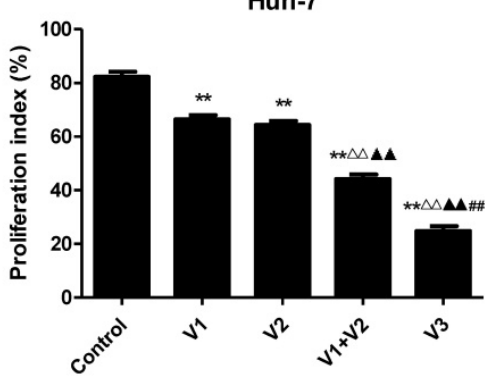

Huh-7

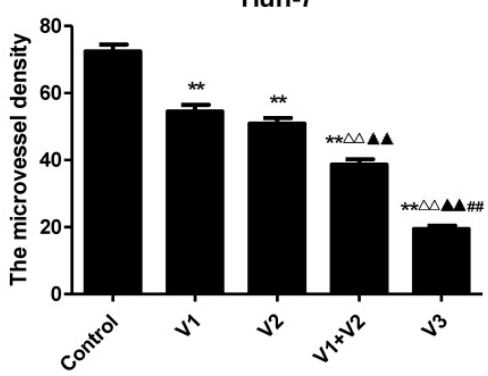

Huh-7

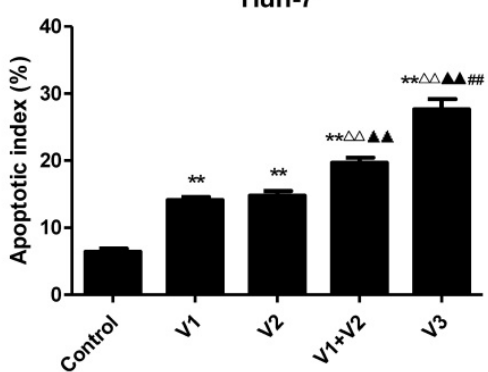

Figure 8. Effects of peptide V3 on the PI, MVD, and apoptosis of human HCC xenografts. (A, B, C, D) Representive photographs of HE, Ki67, CD31, and Cleaved caspase-3 staining in SMMC-7721 and Huh-7 xenograft tumors; original magnification 400x. (E, F, G) The PI, MVD, and apoptotic index were calculated. The PI was calculated by the number of Ki67 positive cells among the total number of resting cells [25]. Stained vessels with a clearly defined lumen or well-defined linear vessel shape were photographed and counted [22]. Apoptotic index was calculated as cleaved caspase 3 positive cells/total cells [27]. Values are presented as mean \pm SEM $(n=6)$; $* * P<0.01$ compared with the control group; $\triangle \triangle P<0.01$ compared with $\mathrm{V} 1$ group; ${ }^{\Delta} P<0.01$ compared with $\mathrm{V} 2$ group; $\# P<0.01$ compared with $\mathrm{V} 1+\mathrm{V} 2$ group 
The binding of different growth factors such as VEGF and Ang to their receptors could induce the activation of RAS which in turn activates RAF, MEK, and ERK [41,42]. The activated ERK translocates into the nucleus and activates transcription factors to promote a number of cellular outcomes [30, 31]. It has been shown that the RAS/RAF/MEK/ERK pathway is in an activated status in the majority of advanced HCC cases [43]. Therefore, the inhibition of this signaling pathway may effectively suppress the growth of HCC, which has been evidenced by many recent studies [44-46]. Our results demonstrated that peptide V3 significantly decreased the protein levels of H-RAS, p-RAF, p-MEK, and p-ERK in human HCC cells, indicating that peptide V3 could inhibit the proliferation, migration, and invasion of human HCC cells by inhibiting the Ras/Raf/MEK/ERK signaling pathway.

A number of studies indicate that SMMC-7721 and Huh-7 cells have been widely adopted to establish subcutaneous xenograft models [22, 34, 35]. We therefore examined the effect of peptide V3 on the growth of human HCC xenograft tumors in BALB/c nude mice. Compared with V1, V2, and V1+V2 group, peptide V3 showed more potent inhibitory effect on the growth of human HCC xenograft tumors, which was in line with our previous findings [19]. It should be noted that the body weight change in $\mathrm{V} 1+\mathrm{V} 2$ group was significantly lower than that in the control group, suggesting that there was a slight toxicity in V1+V2 group. The phenomenon can be attributed to the multidrug-induced high associated toxicity [47]. Ki67, a nuclear non-histone protein, is a key proliferative marker and has been widely used in detecting the proliferation of malignant cells [25, 48]. The results showed that the proliferation index in $\mathrm{V} 3$ group was lower than those in V1, V2, and V1+V2 group. CD31 has been considered an ideal biomarker for vascular endothelial cells and its density is represented by the tumor MVD [26, 49]. The protein expression of CD31 in each group exhibited a similar trend. However, the apoptotic index in V3 group was higher than that in $\mathrm{V} 1, \mathrm{~V} 2$, and V1+V2 group. Taken together, these results indicate that peptide V3 could effectively inhibit the growth of human HCC xenograft tumors by suppressing angiogenesis and up-regulating apoptosis.

In conclusion, peptide V3 could inhibit the growth of human HCC by inhibiting the Ras/Raf/ MEK/ERK signaling pathway. Novel peptides and modification strategies could be designed and applied for the treatment of different types of cancer.

\section{Acknowledgements}

This work was supported by grants from the
National Natural Science Foundation of China (Nos. U1504817, 81670088), the Foundation of Science \& Technology Department of Henan Province, China (Nos. 182102310335, 162300410233, 162300410036, 172 102410019), the Natural Science Foundation of Education Department of Henan Province, China (No. 15A310017), the Science Foundation of Henan University, China (Nos. 16NB048, yqpy20170044), and the Open Fund of State Key Laboratory of Tea Plant Biology and Utilization, China (No. SKLTOF201601 06). Funding bodies did not have any influence in the design of the study and collection, analysis, and interpretation of data or in writing the manuscript.

\section{Competing Interests}

The authors have declared that no competing interest exists.

\section{References}

1. Ma C, Kesarwala AH, Eggert T, et al. NAFLD causes selective CD4(+) T lymphocyte loss and promotes hepatocarcinogenesis. Nature. 2016; 531: 253-7.

2. El-Shamy A, Eng FJ, Doyle EH, et al. A cell culture system for distinguishing hepatitis $C$ viruses with and without liver cancer-related mutations in the viral core gene. J Hepatol. 2015; 63: 1323-33.

3. Patitucci C, Couchy G, Bagattin A, et al. Hepatocyte nuclear factor $1 \mathrm{a}$ suppresses steatosis-associated liver cancer by inhibiting PPARY transcription. J Clin Invest. 2017; 127: 1873-88.

4. Zhu AX, Duda DG, Sahani DV, et al. HCC and angiogenesis: possible targets and future directions. Nat Rev Clin Oncol. 2011; 8: 292-301.

5. Zhu P, Wang Y, Du Y, et al. C8orf4 negatively regulates self-renewal of liver cancer stem cells via suppression of NOTCH2 signalling. Nat Commun. 2015; 6: 7122.

6. Lim KC, Wang VW, Siddiqui FJ, et al. Cost-effectiveness analysis of liver resection versus transplantation for early hepatocellular carcinoma within the Milan criteria. Hepatology. 2015; 61: 227-37.

7. Zhu $\mathrm{P}$, Wang $\mathrm{Y}, \mathrm{Wu}$ J, et al. LncBRM initiates YAP1 signalling activation to drive self-renewal of liver cancer stem cells. Nat Commun. 2016; 7: 13608.

8. Lin F, Marcelo KL, Rajapakshe K, et al. The camKK2/camKIV relay is an essential regulator of hepatic cancer. Hepatology. 2015; 62: 505-20.

9. Reynolds LE, Watson AR, Baker M, et al. Tumour angiogenesis is reduced in the Tc1 mouse model of Down's syndrome. Nature. 2010; 465: 813-7.

10. Vader P, van der Meel R, Symons MH, et al. Examining the role of Rac1 in tumor angiogenesis and growth: a clinically relevant RNAi-mediated approach. Angiogenesis. 2011; 14: 457-66.

11. Wu D, Gao Y, Qi Y, et al. Peptide-based cancer therapy: opportunity and challenge. Cancer Lett. 2014; 351: 13-22.

12. Bonapace L, Coissieux MM, Wyckoff J, et al. Cessation of CCL2 inhibition accelerates breast cancer metastasis by promoting angiogenesis. Nature. 2014; 515: 130-3.

13. Liao $\mathrm{YH}$, Chiang $\mathrm{KH}$, Shieh JM, et al. Epidermal growth factor-induced ANGPTL4 enhances anoikis resistance and tumour metastasis in head and neck squamous cell carcinoma. Oncogene. 2017; 36: 2228-42.

14. Miyake M, Goodison S, Lawton A, et al. Angiogenin promotes tumoral growth and angiogenesis by regulating matrix metallopeptidase-2 expression via the ERK1/2 pathway. Oncogene. 2015; 34: 890-901.

15. Perret GY, Starzec A, Hauet N, et al. In vitro evaluation and biodistribution of a 99mTc-labeled anti-VEGF peptide targeting neuropilin-1. Nucl Med Biol. 2004; 31: 575-81.

16. Starzec A, Vassy R, Martin A, et al. Antiangiogenic and antitumor activities of peptide inhibiting the vascular endothelial growth factor binding to neuropilin-1. Life Sci. 2006; 79: 2370-81.

17. Cao J, Wang R, Gao N, et al. A7RC peptide modified paclitaxel liposomes dually target breast cancer. Biomater Sci. 2015; 3: 1545-54.

18. Tournaire R, Simon MP, le Noble F, et al. A short synthetic peptide inhibits signal transduction, migration and angiogenesis mediated by Tie2 receptor. EMBO Rep. 2004; 5: 262-7.

19. Wu D, Gao Y, Chen L, et al. Anti-tumor effects of a novel chimeric peptide on S180 and H22 xenografts bearing nude mice. Peptides. 2010; 31: 850-64.

20. Wu DD, Gao YR, Li T, et al. PEST-containing nuclear protein mediates the proliferation, migration, and invasion of human neuroblastoma cells through MAPK and PI3K/AKT/mTOR signaling pathways. BMC Cancer. 2018; 18: 499. 
21. Zhang GY, Lu D, Duan SF, et al. Hydrogen Sulfide Alleviates Lipopolysaccharide-Induced Diaphragm Dysfunction in Rats by Reducing Apoptosis and Inflammation through ROS/MAPK and TLR4/NF-kB Signaling Pathways. Oxid Med Cell Longev. 2018; 2018: 9647809.

22. Wu D, Li M, Tian W, et al. Hydrogen sulfide acts as a double-edged sword in human hepatocellular carcinoma cells through EGFR/ERK/MMP-2 and PTEN/AKT signaling pathways. Sci Rep. 2017; 7: 5134.

23. Heilmann AM, Perera RM, Ecker V, et al. CDK4/6 and IGF1 receptor inhibitors synergize to suppress the growth of p16INK4A-deficient pancreatic cancers. Cancer Res. 2014; 74: 3947-58.

24. Ellingson BM, Nguyen HN, Lai A, et al. Contrast-enhancing tumor growth dynamics of preoperative, treatment-naive human glioblastoma. Cancer. 2016; 122: 1718-27.

25. Keam B, Im SA, Lee KH, et al. Ki-67 can be used for further classification of triple negative breast cancer into two subtypes with different response and prognosis. Breast Cancer Res. 2011; 13: R22.

26. Wei W, Mok SC, Oliva E, et al. FGF18 as a prognostic and therapeutic biomarker in ovarian cancer. J Clin Invest. 2013; 123: 4435-48.

27. Chang MY, Rhee YH, Yi SH, et al. Doxycycline enhances survival and self-renewal of human pluripotent stem cells. Stem Cell Reports. 2014; 3: 353-64.

28. Chen $M$, Wang $X, Z$ ha $D$, et al. Apigenin potentiates TRAIL therapy of non-small cell lung cancer via upregulating DR4/DR5 expression in a p53-dependent manner. Sci Rep. 2016; 6: 35468.

29. Pitchakarn P, Suzuki S, Ogawa K, et al. Induction of G1 arrest and apoptosis in androgen-dependent human prostate cancer by Kuguacin J, a triterpenoid from Momordica charantia leaf. Cancer Lett. 2011; 306: 142-50.

30. Lin Z, Zhang $\mathrm{C}$, Zhang $\mathrm{M}$, et al. Targeting cadherin-17 inactivates Ras/Raf/MEK/ERK signaling and inhibits cell proliferation in gastric cancer. PLoS One. 2014; 9: e85296.

31. Kitagawa M, Liao PJ, Lee KH, et al. Dual blockade of the lipid kinase PIP4Ks and mitotic pathways leads to cancer-selective lethality. Nat Commun. 2017; 8: 2200.

32. Wan L, Chen M, Cao J, et al. The APC/C E3 Ligase Complex Activator FZR1 Restricts BRAF Oncogenic Function. Cancer Discov. 2017; 7: 424-41.

33. Peng J, Gassama-Diagne A. Apicobasal polarity and Ras/Raf/MEK/ERK signalling in cancer. Gut. 2017; 66: 986-7.

34. Hou Y, Zou Q, Ge R, et al. The critical role of CD133(+)CD44(+/high) tumor cells in hematogenous metastasis of liver cancers. Cell Res. 2012; 22: 259-72.

35. Huang J, Zheng DL, Qin FS, et al. Genetic and epigenetic silencing of SCARA5 may contribute to human hepatocellular carcinoma by activating FAK signaling. J Clin Invest. 2010; 120: 223-41.

36. Wu D, Si W, Wang M, et al. Hydrogen sulfide in cancer: Friend or foe? Nitric Oxide. 2015; 50: 38-45.

37. Lovell JF, Billen LP, Bindner S, et al. Membrane binding by tBid initiates an ordered series of events culminating in membrane permeabilization by Bax. Cell. 2008; 135: 1074-84.

38. Fan $\mathrm{CD}, \mathrm{Li} \mathrm{Y}, \mathrm{Fu} \mathrm{XT}$, et al. Reversal of Beta-Amyloid-Induced Neurotoxicity in PC12 Cells by Curcumin, the Important Role of ROS-Mediated Signaling and ERK Pathway. Cell Mol Neurobiol. 2017; 37: 211-22.

39. Furlong SJ, Mader JS, Hoskin DW. Lactoferricin-induced apoptosis in estrogen-nonresponsive MDA-MB-435 breast cancer cells is enhanced by C6 ceramide or tamoxifen. Oncol Rep. 2006; 15: 1385-90.

40. Furlong SJ, Ridgway ND, Hoskin DW. Modulation of ceramide metabolism in T-leukemia cell lines potentiates apoptosis induced by the cationic antimicrobial peptide bovine lactoferricin. Int J Oncol. 2008; 32: 537-44.

41. Gourlaouen M, Welti JC, Vasudev NS, et al. Essential role for endocytosis in the growth factor-stimulated activation of ERK1/2 in endothelial cells. J Biol Chem. 2013; 288: 7467-80.

42. Cervello M, McCubrey JA, Cusimano A, et al. Targeted therapy for hepatocellular carcinoma: novel agents on the horizon. Oncotarget. 2012; 3: 236-60.

43. Gao JJ, Shi ZY, Xia JF, et al. Sorafenib-based combined molecule targeting in treatment of hepatocellular carcinoma. World J Gastroenterol. 2015; 21: 12059-70.

44. Zhou K, Luo X, Wang Y, et al. MicroRNA-30a suppresses tumor progression by blocking Ras/Raf/MEK/ERK signaling pathway in hepatocellular carcinoma. Biomed Pharmacother. 2017; 93: 1025-32.

45. Zhang $\mathrm{Q}$, Wei L, Yang $\mathrm{H}$, et al. Bromodomain containing protein represses the Ras/Raf/MEK/ERK pathway to attenuate human hepatoma cell proliferation during HCV infection. Cancer Lett. 2016; 371: 107-16.

46. Yang S, Liu G. Targeting the Ras/Raf/MEK/ERK pathway in hepatocellular carcinoma. Oncol Lett. 2017; 13: 1041-7.

47. Lee WH, Loo CY, Leong CR, et al. The achievement of ligand-functionalized organic/polymeric nanoparticles for treating multidrugresistant cancer. Expert Opin Drug Deliv. 2017; 14: 937-57.

48. Yerushalmi R, Woods R, Ravdin PM, et al. Ki67 in breast cancer: prognostic and predictive potential. Lancet Oncol. 2010; 11: 174-83.

49. Tolaney SM, Boucher $\mathrm{Y}$, Duda DG, et al. Role of vascular density and normalization in response to neoadjuvant bevacizumab and chemotherapy in breast cancer patients. Proc Natl Acad Sci USA. 2015; 112: 14325-30. 